\title{
Pipe loop tests at Codelco pilot plant
}

\author{
L. Martinson Paterson \& Cooke, Chile \\ R. Martinson Paterson \& Cooke, Chile \\ R. Cooke Paterson \& Cooke, USA
}

\begin{abstract}
The pipeline transport of high density thickened tailings presents interesting design challenges in considering the implementation of a tailings disposal system. The project must define the type and level of the tests to be performed in order to obtain sufficient good quality data to be incorporated in the project design basis. This was the case of the Codelco Norte Future Tailings feasibility engineering project, where a pilot plant was constructed and operated on the mine site.

The Codelco Norte project considered a tailings tonnage of 230,000 tpd (metric tonnes per day) with an available tailings dam surface area of $50 \mathrm{~km}^{2}$. The design basis established from the pilot plant tests has two significant impacts on the project:
\end{abstract}

- Identification of feasible technical solutions to be investigated in subsequent phases of the project.

- The setting of appropriate design factors (considering uncertainties and risks) to minimise the project capital and operating costs.

The pilot test program included the design and construction of a pipe loop for conducting tests related with the pipeline transport of high density thickened tailings. A centrifugal slurry pump was used and 75 and $100 \mathrm{~mm}$ pipe loops, both with transparent sections, were installed.

This paper describes the general configuration of the pilot plant, specifically the pipe loop tests. The most important and interesting findings are presented, with a focus on aspects related to the tailings rheology, deposition velocity, laminar flow segregation and pump performance derating.

\section{Introduction}

The global scarcity of fresh water is an important issue for mining projects; water is becoming increasingly expensive, forcing mining companies to minimise water consumption (often through the implementation of new tailings management technologies, which may have higher capital and operating costs than conventional systems).

High density thickened tailings systems are attractive due to the potential for mine water savings and increased tailings facility storage capacity. The project specific tailings management system design parameters must be accurately defined before the feasibility of the technology can be investigated.

In terms of high-density thickened tailings pipeline transportation, pilot pipe loop tests can provide the required design parameters for the hydraulic design of the system. Specific flow behaviour tests define key aspects of the pipeline transport design criteria.

A pilot plant was constructed for the Codelco Norte Future Tailings feasibility engineering project, which evaluated a wide range of tailings mass concentrations based on a tailings tonnage of 230,000 tpd and an available tailings dam surface area of $50 \mathrm{~km}^{2}$.

This paper describes the pipe loop tests executed and the more interesting and valuable results used to generate the final design basis for the engineering for the Codelco Norte Future Tailings feasibility engineering project. 
The pilot plant at Codelco Norte was designed and operated by Paterson \& Cooke (P\&C), Knight Piésold (KP), ATC Williams and Outotec during the period January to May 2011.

\section{$1.1 \quad$ Pilot plant description}

The pilot plant was developed with the purpose of measuring key design parameters for the tailings management system in relation to thickening, transport and deposition.

The main elements of the pilot plant are shown in Figure 1.

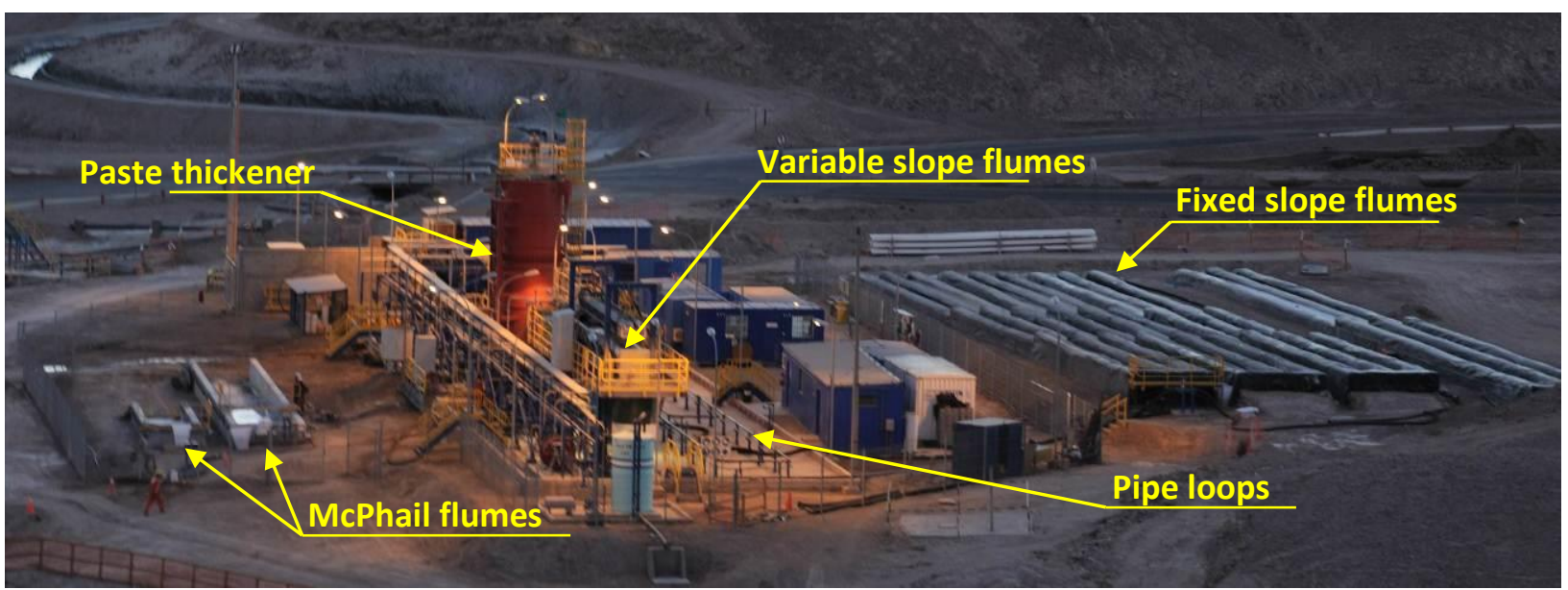

Figure 1 Pilot plant main components

\subsubsection{Paste thickener and storage tank}

The 70 tpd paste thickener ( $9 \mathrm{~m}$ high and $2.5 \mathrm{~m}$ diameter) was operated by Outotec. The thickened slurry was stored in a $25 \mathrm{~m}^{3}$ tank. Peristaltic pumps (Bredel SPXs) distributed thickened tailings to the various components of the pilot plant.

\subsubsection{Variable slope flume}

The variable slope flume was designed and operated by ATC Williams. Thickened tailings were delivered to the flume at a maximum flow rate of $18 \mathrm{~L} / \mathrm{s}$.

\subsubsection{McPhail fixed flumes}

The fixed flumes were designed by Gordon McPhail and operated by KP. Two flumes were constructed: A small flume $(1.8 \mathrm{~m}$ wide, $8 \mathrm{~m}$ long and $0.7 \mathrm{~m}$ high) for a tailings feed of $1 \mathrm{~L} / \mathrm{s}$, and a larger flume $(2.5 \mathrm{~m}$ wide, $20 \mathrm{~m}$ long and $1 \mathrm{~m}$ high) for a tailings feed of $10 \mathrm{~L} / \mathrm{s}$. The flumes were constructed of concrete with adverse slope of $0.5 \%$.

\subsubsection{Fixed slope flumes}

Eight $50 \mathrm{~m}$ length fixed slope flumes were designed and operated by KP. They were grouped in pairs for evaluating specific tailings samples; one with underdrainage and the other with no drainage.

\subsubsection{Pipe loop}

P\&C designed and operated the pipe loop facility, which was comprised of 75 and $100 \mathrm{~mm}$ pipe steel piping, a centrifugal slurry pump to recirculate the tailings slurry through the loops, and a $3 \mathrm{~m}^{3}$ mixing tank. The following section describes the pipe loop facility in more detail. 


\section{$2 \quad$ Pipe loop}

The viscous properties evaluation, the flow behaviour tests (described in detail in Section 4) and the comparison between the experimental data and theoretical pressure loss models were the main objectives for the pipe loop tests. As shown in Figures 2 and 3, the pipe loop facility comprises the following components:

- Slurry pump: A Warman-Vulco 4" $\times 3$ " slurry centrifugal pump equipped with a mechanical seal and $150 \mathrm{hp}$ variable speed drive was used to circulate the slurry through the loops.

- Mix and head tank: The $3 \mathrm{~m}^{3}$ conical bottom tank was equipped with a two impeller agitator to ensure homogenous sample mixing.

- Flow meter: A Coriolis flow meter was used to measure volumetric flow rate, mass flow rate and temperature.

- Pipe loops: The 75 and $200 \mathrm{~mm}$ steel pipe loops, connected using Vitaulic couplings, were $70 \mathrm{~m}$ and $100 \mathrm{~m}$ long respectively. Both pipe loops were equipped with sections of transparent PVC pipe to allow observation of the thickened tailings slurry flow behaviour. The loops were also provided with sampling points at the top and bottom of the pipe.

- Heat exchanger: Both pipe loops were equipped with heat exchangers connected to an evaporative cooling tower to maintain the slurry temperature during the tests.

- Instrumentation: Four differential pressure transmitters were installed, two for each pipe loop diameter to measure pipe pressure loss. Absolute pressure transmitters were provided for the suction and discharge of the pump to evaluate the pump performance. The loop was also equipped with a temperature sensor. The variable speed drive provided information related to the electrical power and speed of the motor.

The double measurement of differential pressure for each pipe loop allowed the readings to be checked and provided a test acceptance criterion. The differential pressure measurement locations were selected to provide disturbance-free steady state flow in the measurement sections.

The data-logging system provided by $\mathrm{P} \& \mathrm{C}$ allowed real time verification of the all the measurements during the execution of a test.

A laboratory within the plant was used to obtain the slurry properties such as mass concentration by oven drying, $\mathrm{pH}$, slump tests and rheology using a rotational viscometer Haake VT550. Due to the coarse particle size distribution and particle segregation observed during the test, the rheology of only a few samples could be measured with the rotational viscometer and for this reason the authors decided not include these results. 


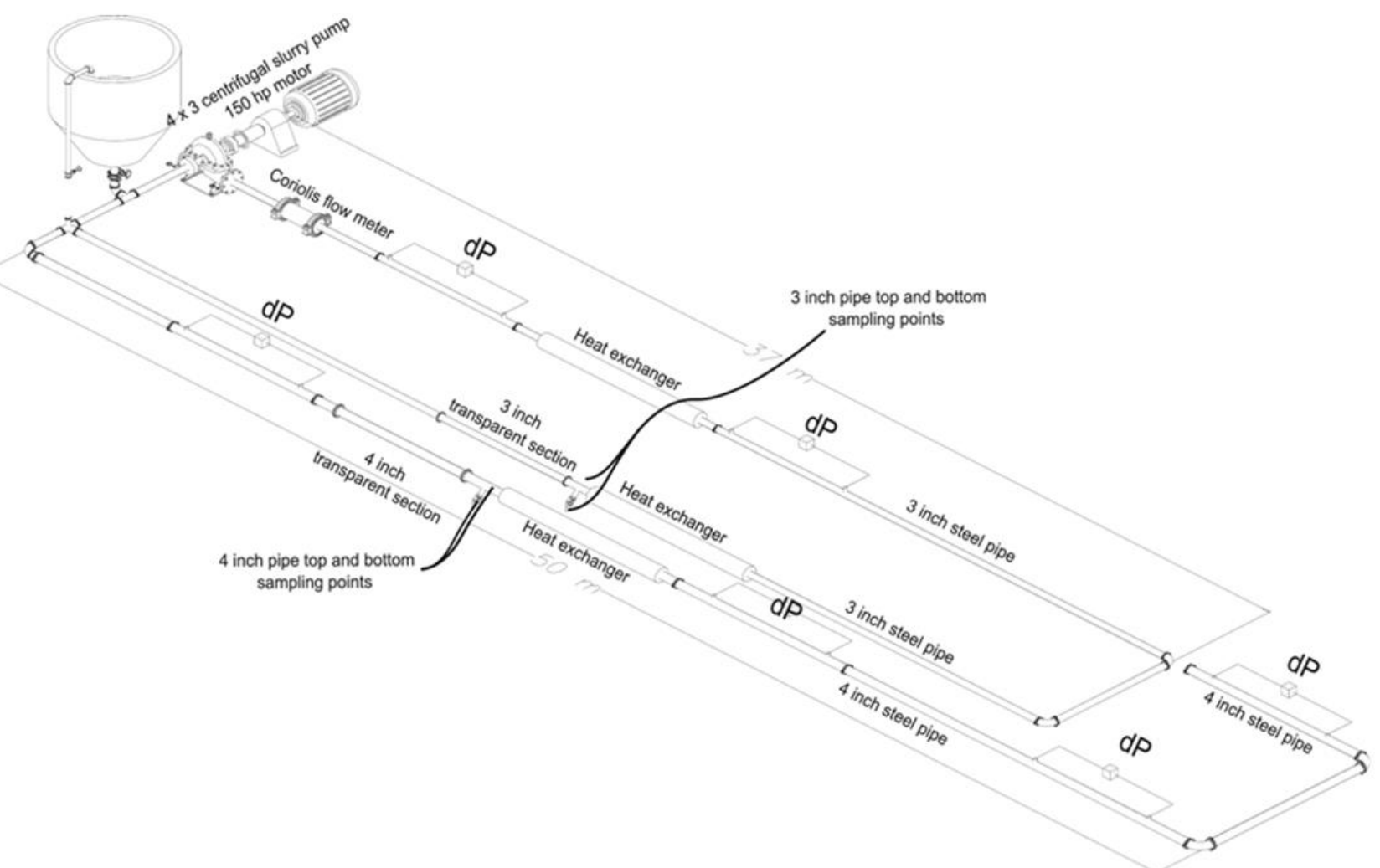

Figure 2 Pipe loop schematic illustration of the layout and instrumentation
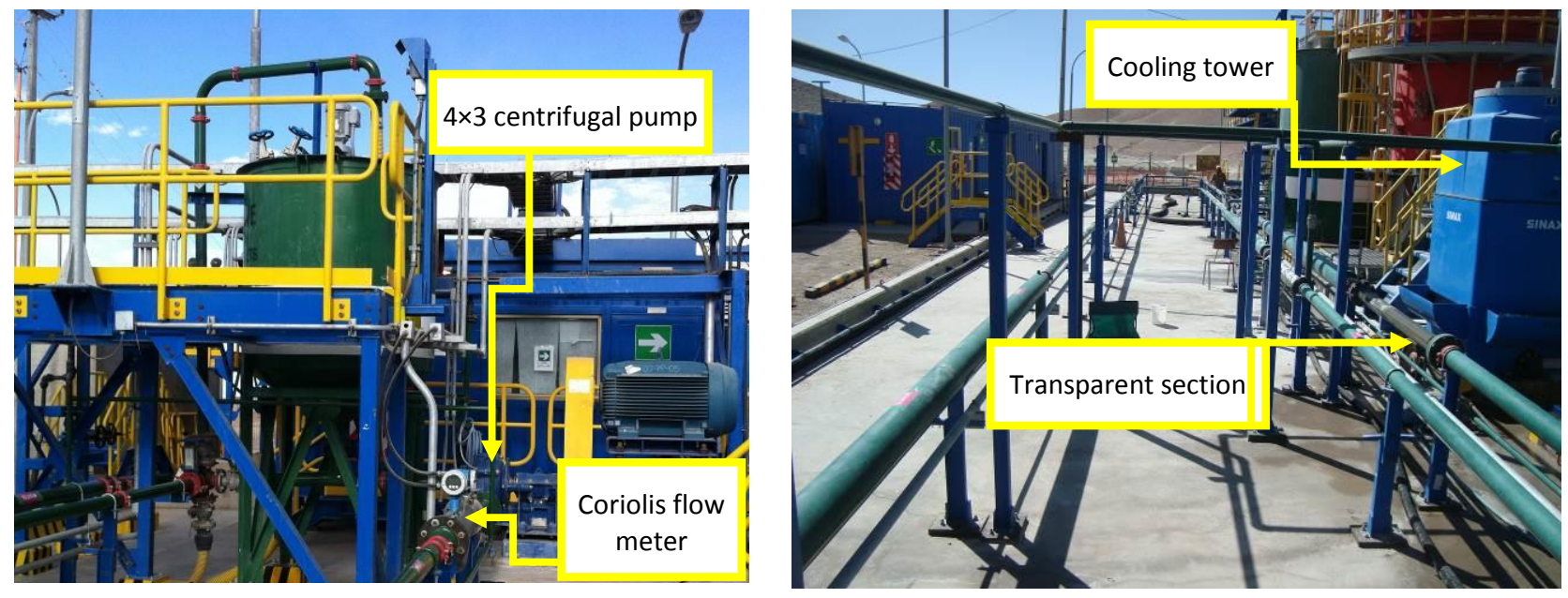

Figure 3 Main pipe loop components

\section{$3 \quad$ Pilot test work challenge}

Brown and Heywood (1991) noted the following:

"Pilot-plant testing is advisable if a new slurry pipeline installation is planned. (...) A properly designed pilot-plant flow loop will have much greater flexibility and will be capable of producing data over a wider range of conditions than an operating pipeline. This wide range of test conditions is required to develop a good understanding of the flow behaviour of the slurry." 
The value of pipe loop tests is much greater than just friction loss measurements and flow behaviour observations. Pilot tests provide an opportunity to evaluate the performance of process equipment and to familiarise the client with thickened tailings and associated processes.

For thickened tailings projects, the following issues should be addressed (Cooke, 2002):

- What is the minimum velocity that the system can be operated at?

- Can the pressure gradients be scaled to larger pipe sizes?

- Will the coarse particles settle?

- Will particle settling cause the pressure gradient to increase?

- Can coarse particles be flushed out of the pipeline if they settle?

The challenge is to be able to answer these questions based on information gained from the pilot pipe loop tests.

\section{$4 \quad$ Pilot test results}

The most interesting and important results from the pilot pipe loop test are described in this section.

\subsection{Test plan description and results}

The test plan considered the following:

- Basic tailings properties.

- Flow curve measurements.

- Rheology.

- Laminar to turbulent transition velocity (not discussed in this paper).

- Turbulent flow deposition velocity (not included in this paper).

- Centrifugal pump performance evaluation.

- Pipe loop re-start test.

- Evaluation of laminar flow segregation.

It is important to note that the last two tests were qualitative; they were not intended for extrapolation to larger pipe diameters.

\subsubsection{Basic tailings properties}

Due to the large quantity of samples generated during the pilot test work, the tailings particle size distribution (PSD) and solids density were measured by a certified external laboratory. The PSD was obtained according to the ASTM D422 standard method and the specific gravity according to the Chilean standard NCh 1532.0 f80 based on the ASTM D854-10 standard method.

A wide range of tailings characteristics, as shown in Figure 4, were obtained during the five months of operating the pilot plant.

The particle characteristic diameters for upper, average and lower PSD curves are shown in Table 1.

The PSD variability observed during the operating period was mostly a consequence of a scheduled shutdown for concentrator plant maintenance for two days which resulted in coarser tailings being produced during the start-up period. The tailings are relatively coarse compared with typical copper tailings. 

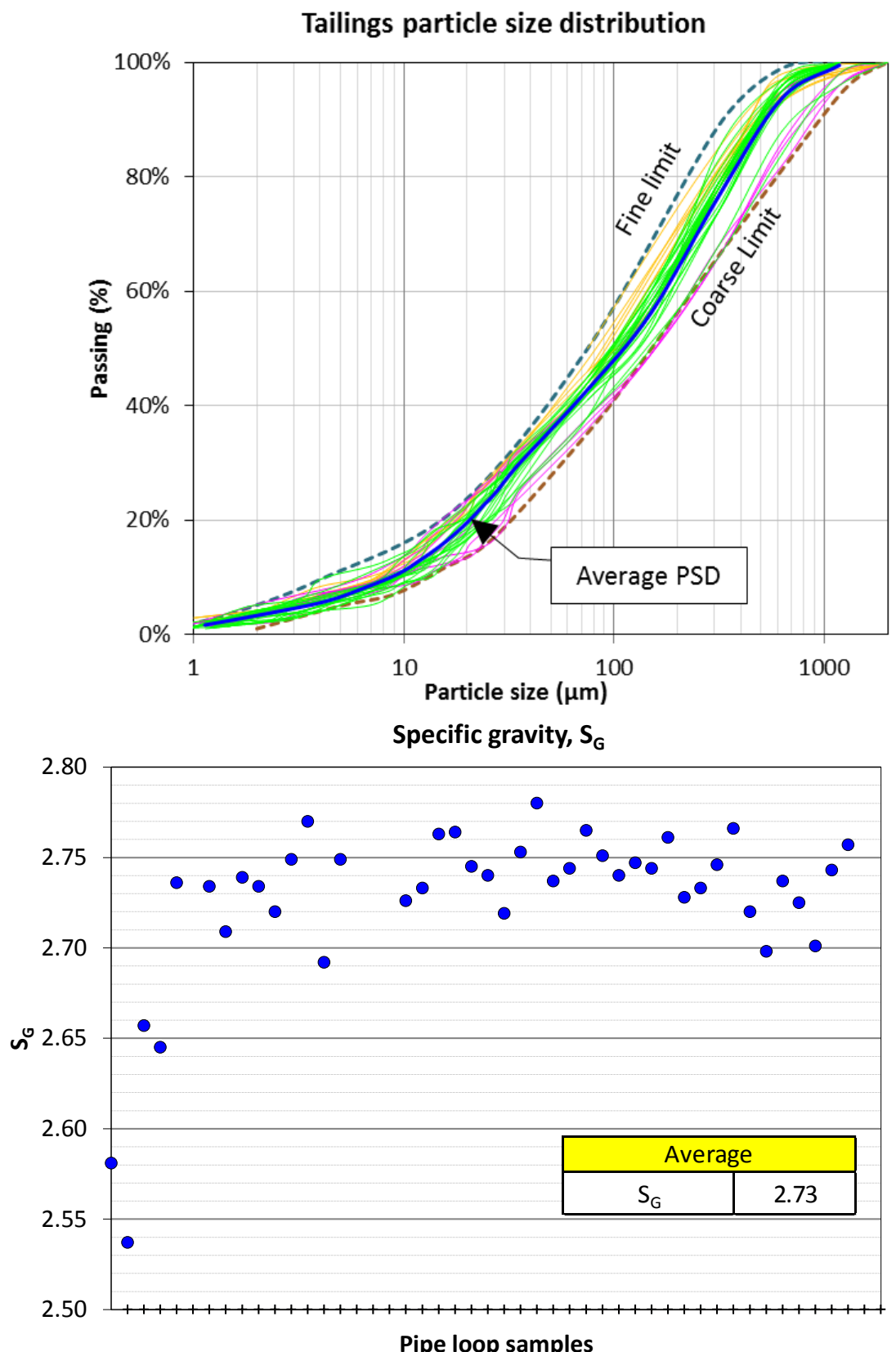

Figure 4 PSD and $S G$ recorded values - all samples

\section{Table 1 Slurry particle size properties}

\begin{tabular}{lcccc}
\hline Parameter & & Fine limit & Average & Coarse limit \\
\hline Particle diameter, $\mathrm{d}_{10}$ & $(\mu \mathrm{m})$ & 4 & 9 & 13 \\
Particle diameter, $\mathrm{d}_{20}$ & $(\mu \mathrm{m})$ & 14 & 21 & 32 \\
Particle diameter, $\mathrm{d}_{50}$ & $(\mu \mathrm{m})$ & 75 & 109 & 151 \\
Particle diameter, $\mathrm{d}_{80}$ & $(\mu \mathrm{m})$ & 226 & 351 & 597 \\
Particle diameter, $\mathrm{d}_{90}$ & $(\mu \mathrm{m})$ & 338 & 483 & 956 \\
Percentage of fines, $-75 \mu \mathrm{m}$ & $(\%)$ & 50 & 43 & 35 \\
Specific gravity, $\mathrm{S}_{\mathrm{G}}$ & $(-)$ & - & 2.73 & - \\
\hline
\end{tabular}




\subsubsection{Flow curve measurements}

A flow curve is a graphical representation of slurry flow behaviour when it is subjected to ascending or descending shear rates plotted as wall shear stress versus shear rate. For pipe flow, the flow curve is termed a pseudo shear diagram as it is a plot of pipe wall shear stress (determined from the measured friction pressure loss) versus pseudo shear rate (determined from the pipe velocity and diameter) as defined by the following equations:

$$
\begin{gathered}
\tau_{0}=\frac{D}{4}\left(\frac{\Delta P}{\Delta L}\right) \\
\Gamma=\frac{8 V}{D}
\end{gathered}
$$

Where:

$$
\begin{array}{ll}
\tau_{0} & =\text { pipe wall shear stress }(\mathrm{Pa}) . \\
\Delta P / \Delta L & =\text { friction pressure loss }(\mathrm{Pa} / \mathrm{m}) . \\
\Gamma & =\text { pseudo shear rate }\left(\mathrm{s}^{-1}\right) . \\
V & =\text { pipe velocity }(\mathrm{m} / \mathrm{s}) . \\
D & =\text { internal pipe diameter }(\mathrm{m}) .
\end{array}
$$

Laminar flow data from different pipe diameters will be coincidental on a pseudo shear diagram provided the flow is homogenous, uniform and there is no slip (for the same slurry mixture).

The flow curves obtained from a pipe loop test provide the following information:

- The rheology of the slurry can be established by fitting the appropriate equation to the laminar flow data, for example, the Buckingham equation for a slurry that may be characterised as a Bingham plastic mixture.

- Identification of the transition velocity between laminar and turbulent flow.

- Turbulent flow pressure loss data.

Figure 5 presents pseudo shear diagram data from the pilot tests (the solid and open data points are for the 75 and $100 \mathrm{~mm}$ pipe loops respectively):

- There is good agreement between the 75 and $100 \mathrm{~mm}$ laminar flow data.

- Only laminar flow data was obtained in the $100 \mathrm{~mm}$ pipe loop for this data set.

- For the $75 \mathrm{~mm}$ pipe, turbulent flow data was measured for solids concentrations below $66 \% \mathrm{cw}$. For higher solids concentrations only laminar flow data was recorded in the $75 \mathrm{~mm}$ pipe loop.

Figure 7 compares experimental data from the $100 \mathrm{~mm}$ pipe loop with the following models:

- The curves for the laminar flow data are calculated using the Buckingham equation with Bingham plastic rheological parameters obtained from fitting the Buckingham equation to the measured data.

- The turbulent flow curves are calculated using the Thomas and Wilson model (2007). The model reasonably predicts the $63.3 \% \mathrm{cw}$ data although there is some over prediction at higher velocities.

As is mentioned in Section 2, it was not possible to measure flow curves using the rotational viscometer due to particle settling during the measurement. 


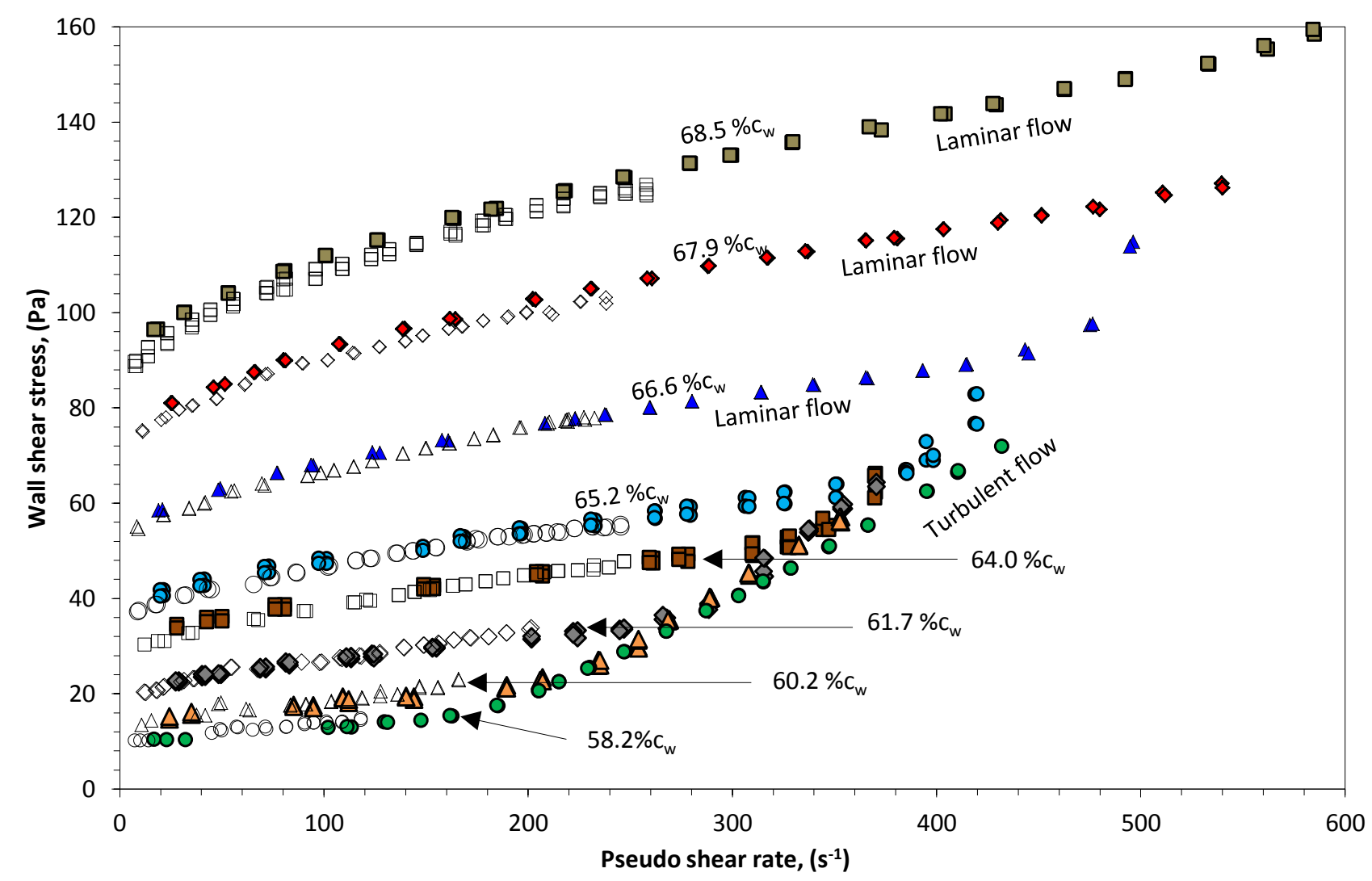

Figure 575 and $100 \mathrm{~mm}$ pipe loop flow curves

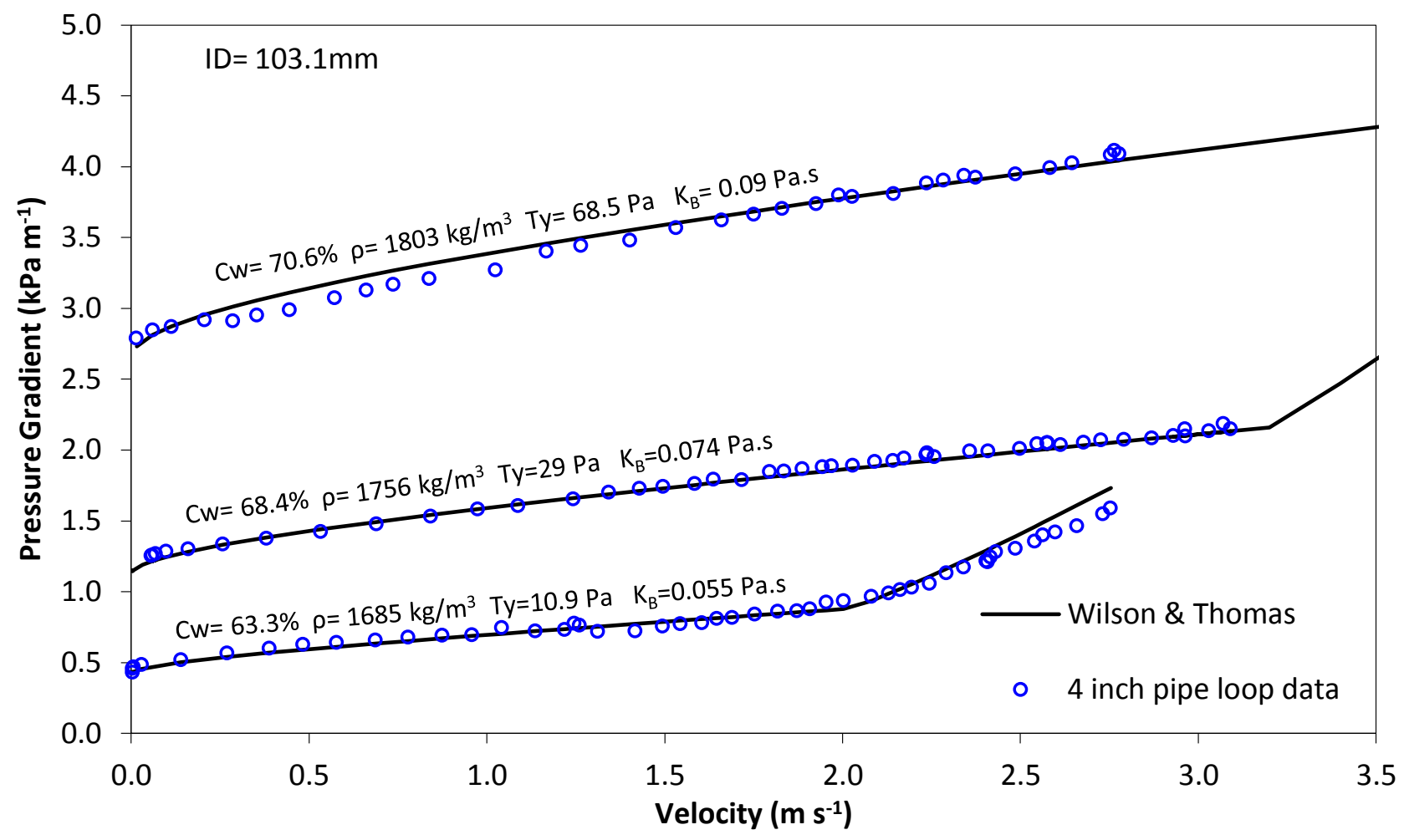

Figure 6 Model comparison with $100 \mathrm{~mm}$ pipe loop data 


\subsubsection{Rheology}

The Bingham plastic model was found to best characterise the rheology of the thickened tailings (fully sheared condition, $\mathrm{pH}$ between 8.0 and 9.0).

Figure 7 shows the wide range rheologies derived from the pilot loop measurements. For example, for a solids concentration of $67 \% \mathrm{cw}$ the yield stress varies between 20 and $53 \mathrm{~Pa}$. This variability correlates with the PSD variation mentioned previously; the finer the sample, the greater rheology for an equivalent mass concentration.

\subsubsection{Centrifugal pump performance evaluation}

In order to evaluate the reduction in centrifugal pump performance when operating with thickened tailings, the pump head generated was measured for a series of tailings concentrations and was compared with the vendor curve and with clear water tests.

The tests were conducted at pump speeds of 1,900 and 1,630 rpm, and for tailings concentrations of $62.8 \%$ and $70.7 \%$ (corresponding to yield stresses of 11.5 and 71.0 Pa respectively).

Figure 8 shows the measured pipe loop data on the vendor pump performance chart. The clear water data has a good correlation with the vendor pump curve. Figure 9 shows there is reasonable correlation between the measured pump head derating and the Walker and Goulas (1984) method.
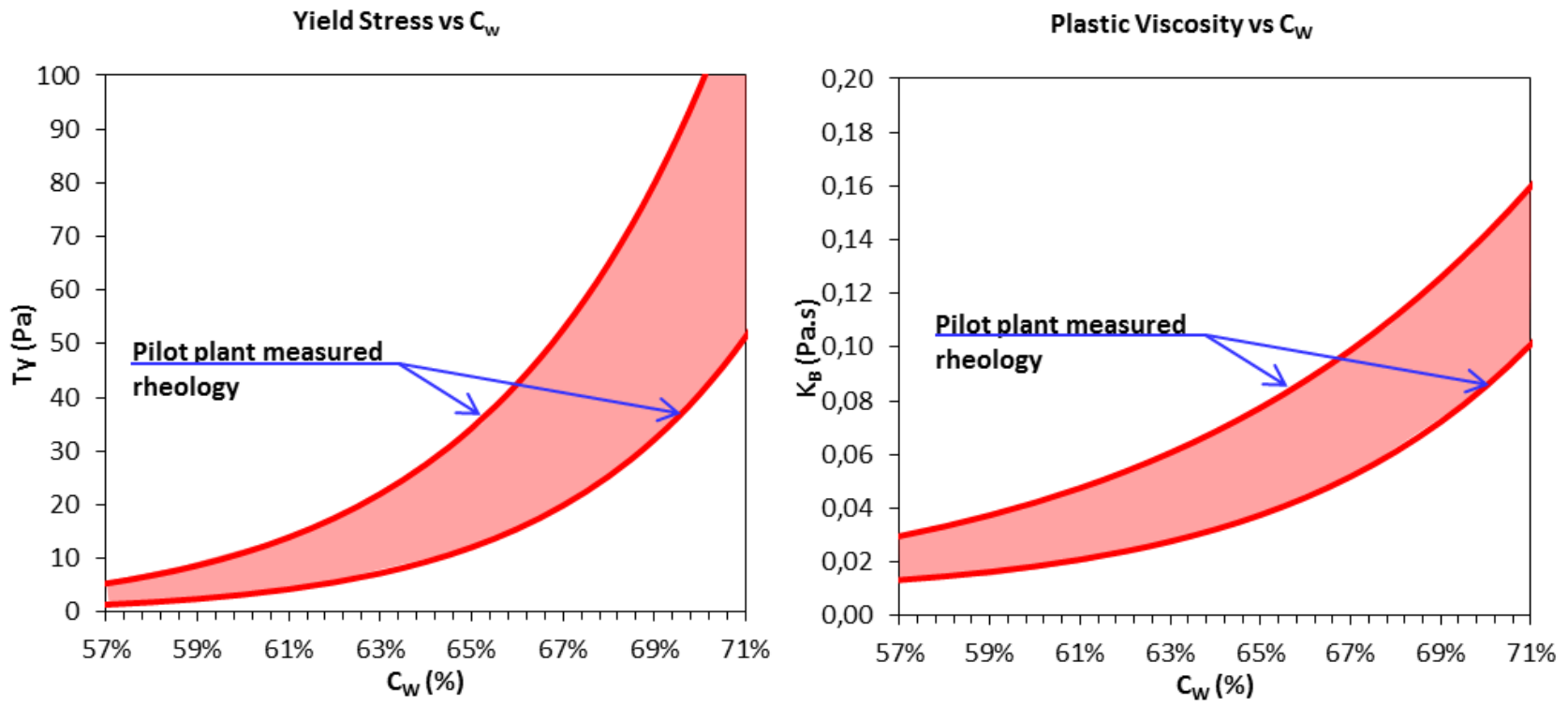

Figure 7 Rheology derived from pilot plant measurements 


\begin{tabular}{|c|c|c|c|c|c|c|c|}
\hline \multirow{8}{*}{ PUMP GRour } & \multirow{5}{*}{$\begin{array}{c}\begin{array}{c}\text { PUMP } \\
\text { SIZE }\end{array} \\
4 / 3 \\
T Y P E\end{array}$} & FRAME & KWRATING & \multirow{5}{*}{\multicolumn{3}{|c|}{$\begin{array}{c}\text { For contact details - } \\
\text { visit www.warman.co.za }\end{array}$}} & \multirow{9}{*}{$\begin{array}{c}\text { PUMP } \\
\text { PERFORMANCE } \\
\text { CURVE } \\
\text { REFERENCE } \\
\\
\text { WPG } \\
\text { 43AH30 } \\
\text { Reprinted } \\
\text { June } 2004\end{array}$} \\
\hline & & CAM & 30 & & & & \\
\hline & & CCAM & 55 & & & & \\
\hline & & $\mathbf{D}^{*}$ & 60 & & & & \\
\hline & & & 110 & & & & \\
\hline & & IMP & ELLER & & 47 & LINER & \\
\hline & & VANES & TYPE & $M A T^{\prime} L$ & VANE $O$ & $M A T^{\prime} L$ & \\
\hline & & 5 & CLOSED & METAL & 245 & METAL & \\
\hline COPYRIGHT @ RESEAR & AND DEVELC & T PTY LTD & & $A N D S E$ & $L P U M P$ & & \\
\hline $\begin{array}{r}\text { WE RESERVE THE RI } \\
\text { IMPELLERS V }\end{array}$ & HOUT PRIOR N & & POFER CONSUM & TON MAY INCREA & BY $5 \%$ WTTH CENT & RRIFUGAL SEAL & MIN PASSAGE SIZE \\
\hline $\begin{array}{l}\text { CURVE SHOWS APPROXI } \\
\text { WITH PUMP TESTING ISC } \\
\text { THAN WATER, CORRECT } \\
\text { PRESENCE AND EFFECT }\end{array}$ & $\begin{array}{l}\text { TE PERFORM } \\
\text { D6-1999 GRADE } \\
\text { VS MUST BE M } \\
\text { F SOLIDS }\end{array}$ & $\begin{array}{l}\text { OR CLEAR W } \\
\text { 548 CLASS C), } \\
\text { R DENSITY, }\end{array}$ & $\begin{array}{l}\text { TATER (INACCORI } \\
\text { j. FOR MEDIA OTH } \\
\text { VISCOSITY AND/OI }\end{array}$ & & $\begin{array}{r}\text { NORM MAX } \\
275\end{array}$ & $R P M$ & $\begin{array}{l}36 \mathrm{~mm} \\
\text { SPHERE }\end{array}$ \\
\hline
\end{tabular}

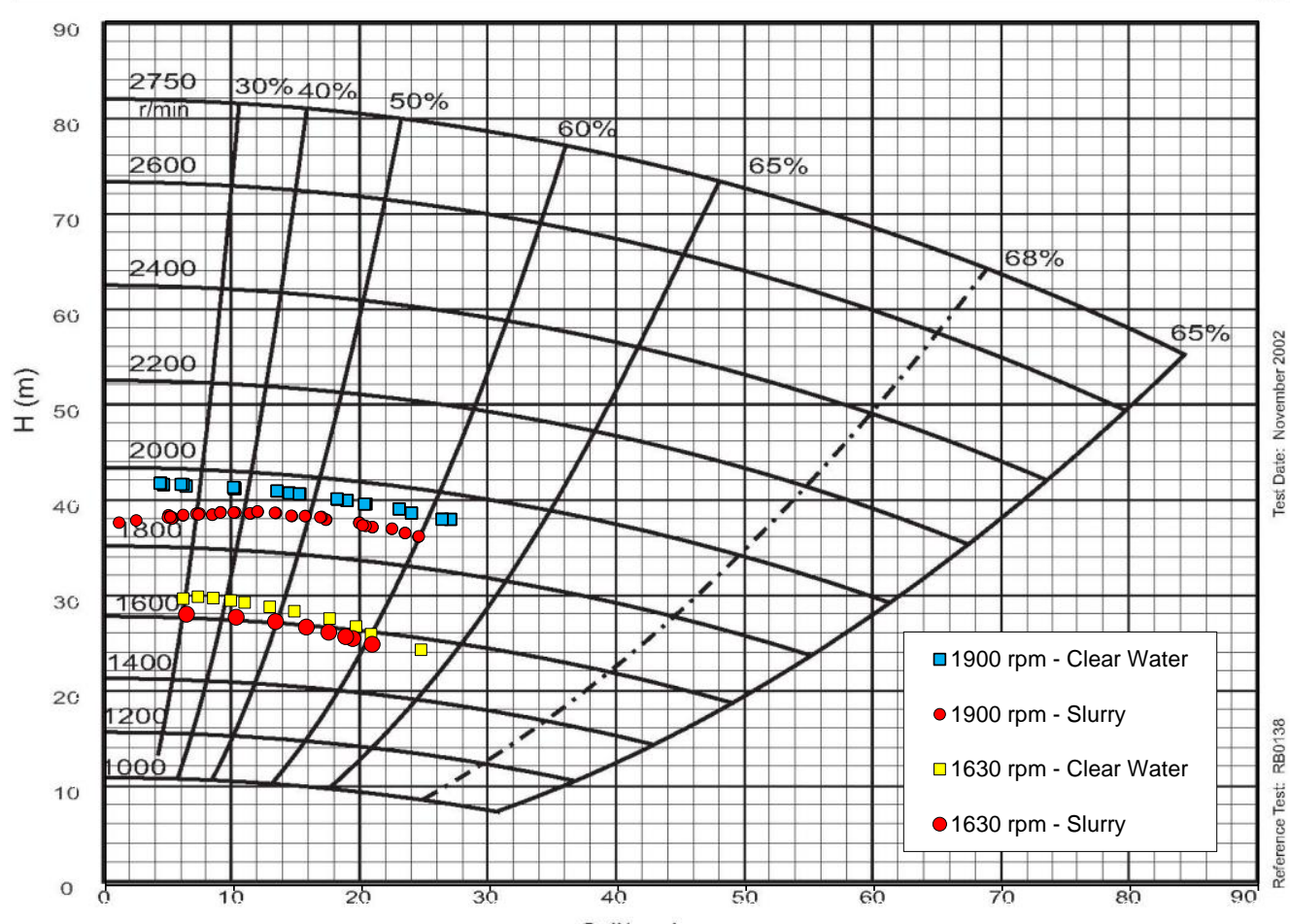

Figure 8 Pump performance curves (1,900 and 1,630 rpm) 


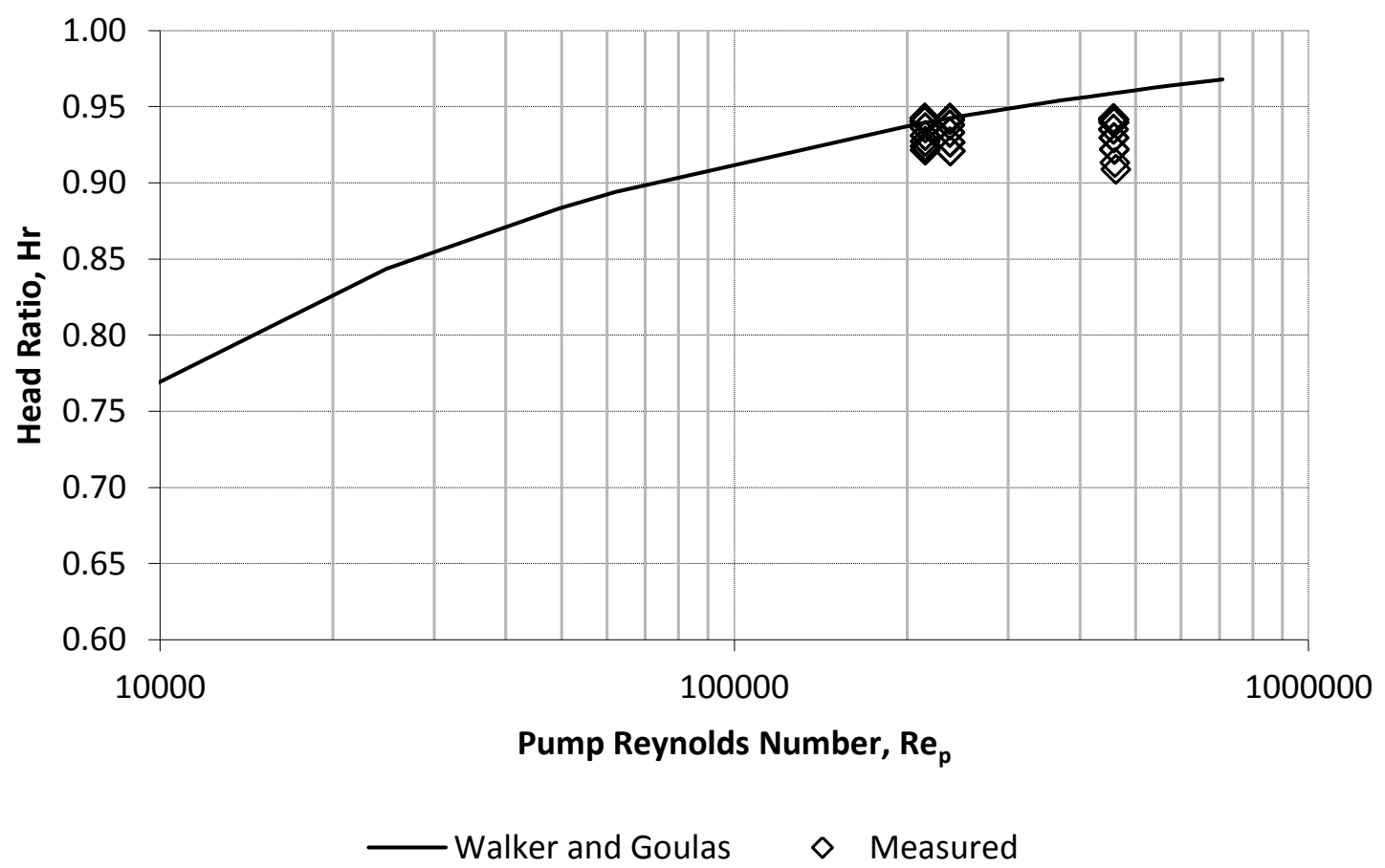

Figure 9 Pump head derating: Walker and Goulas versus measured data

\subsubsection{Re-start tests}

The re-start tests comprised measuring a flow curve which ideally reaches the turbulent flow condition and then the flow is stopped and left quiescent for a one-hour period. After the one-hour period, the system is restarted gradually while recording the pipeline gradient.

Figure 10 shows the results of a re-start test performed at a solids concentration of $67.4 \%$ with a yield stress of $27.5 \mathrm{~Pa}$. After the one-hour quiescent period, clear water was observed on top of the pipe; during re-start this water started to flow first gradually re-suspending the solids bed.
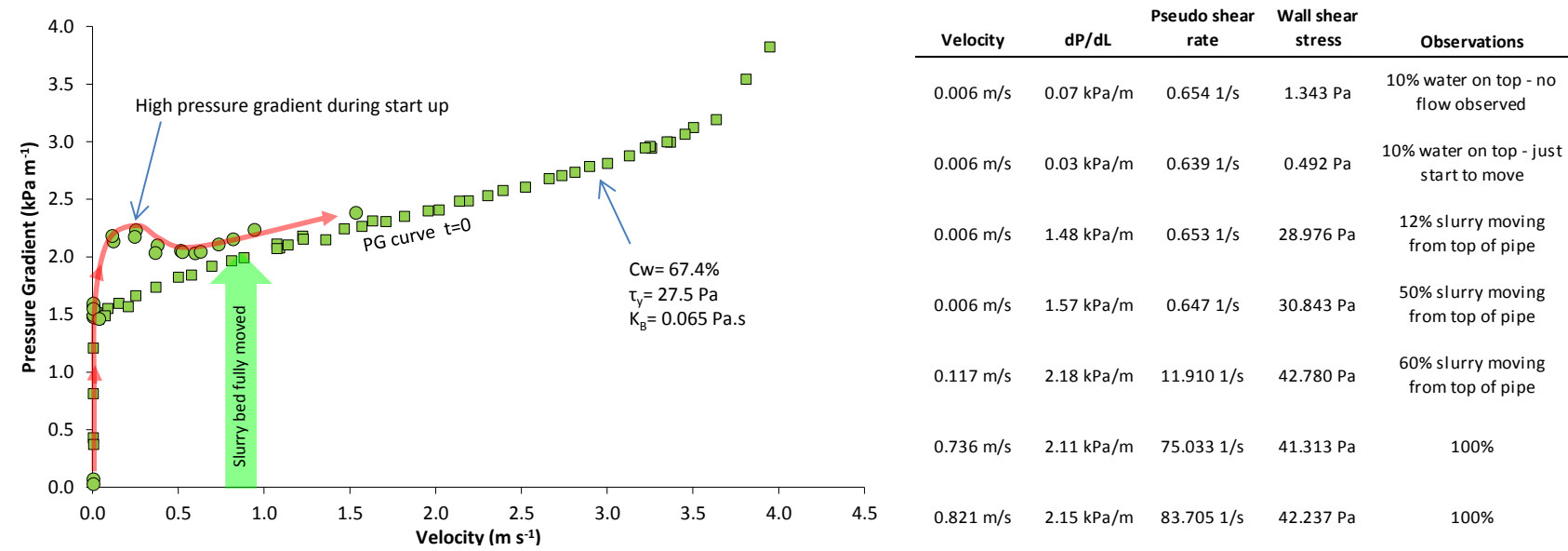

Figure 10 Re-start tests (75 mm pipe $-67.4 \% \mathrm{cw}$ )

\subsubsection{Laminar segregation tests}

Any project that considers operating with highly thickened tailings must evaluate the potential for coarse particle segregation under laminar flow conditions. The high operating velocities (with associated high pressure gradients) required to achieve turbulent flow for slurries with yield stresses greater than $40 \mathrm{~Pa}$ make it attractive to consider laminar flow operation to potentially reduce energy consumption. 
In laminar flow, coarse particles within the slurry will tend to settle when the slurry is sheared. This results in non-homogenous laminar flow (with larger particles, a higher solids concentration and increased rheology towards the bottom of the pipe). Under these conditions, standard methods for predicting pressure gradient are no longer valid. There is also risk that coarse particles could form a stationary bed on the pipe invert further increasing the pressure gradient.

To investigate this issue, a flow curve was measured and then the system run in laminar flow conditions at a velocity close to $2.5 \mathrm{~m} / \mathrm{s}$ (a typical industrial condition) for a period of one hour at a fixed pump speed. Samples were collected from the top and bottom of the pipe at the start of the test and every 15 minutes in order to identify if any particle segregation occurred.

The laminar segregation test data are shown in Table 2 and Figure 11. The results show that the pressure gradients increased permanently with respect to the original flow condition recorded suggesting that laminar flow segregation occurred during the tests. The percentage increase in pressure gradient tends to rise with increasing solids concentration. During the $68.7 \% \mathrm{cw}$ test, after one hour of fixed pump speed operation and reducing the flow rate to zero to measure the flow curve, it was found that it was not possible to restart the system due to the complete blockage of the pipe.

Figure 12 , comparing the percentage $+825 \mu \mathrm{m}$ material in samples collected from the top and bottom of the pipe, confirms that particle segregation occurred for all the concentrations tested. The degree of segregation appears to decrease with increasing yield stress.

There was no evidence of particle degradation during the tests; the PSD of fully mixed samples (i.e. with the loop operating in turbulent flow) collected before and after each test were co-incident.

In a recirculating pipe loop, the degree of segregation is limited, as there is a finite population of coarse particles due to the fixed system volume. This limit does not exist for industrial operations and this phenomenon should ideally be investigated in once through systems (rather than re-circulating loops).

It was concluded that it is not feasible to base the project design on laminar flow operation due to the risk of additional energy required and the potential of blocking the system.

Table 2 Slurry properties - laminar settling: 75 and $100 \mathrm{~mm}$ pipe loop tests

\begin{tabular}{lcccccccc}
\hline Pipe loop diameter & $\mathbf{4}$ in & $\mathbf{4}$ in & $\mathbf{4}$ in & $\mathbf{4}$ in & $\mathbf{3}$ in & $\mathbf{3}$ in & $\mathbf{3}$ in & $\mathbf{3}$ in \\
\hline Mass concentration, $\mathrm{C}_{\mathrm{w}}(\%)$ & 70.7 & 68.7 & 67.5 & 62.8 & 69.6 & 68.3 & 67.4 & 62.3 \\
Density, $\rho_{\mathrm{m}}\left(\mathrm{kg} / \mathrm{m}^{3}\right)$ & $1,804.3$ & $1,761.5$ & $1,741.5$ & $1,681.4$ & $1,782.4$ & $1,752.0$ & $1,747.0$ & $1,662.0$ \\
Yield stress, $\tau_{\mathrm{y}}(\mathrm{Pa})$ & 71.0 & 39.5 & 29.5 & 11.5 & 81.5 & 36.3 & 28.0 & 11.0 \\
Plastic Viscosity, $\mathrm{K}_{\mathrm{B}}$ (Pa.s) & 0.099 & 0.080 & 0.075 & 0.050 & 0.090 & 0.072 & 0.068 & 0.033 \\
$\begin{array}{l}\text { Increase of pressure gradient } \\
\text { after one hour }(\%)\end{array}$ & 28 & 30 & 21 & 13 & 11 & 16 & 14 & 12 \\
\hline
\end{tabular}




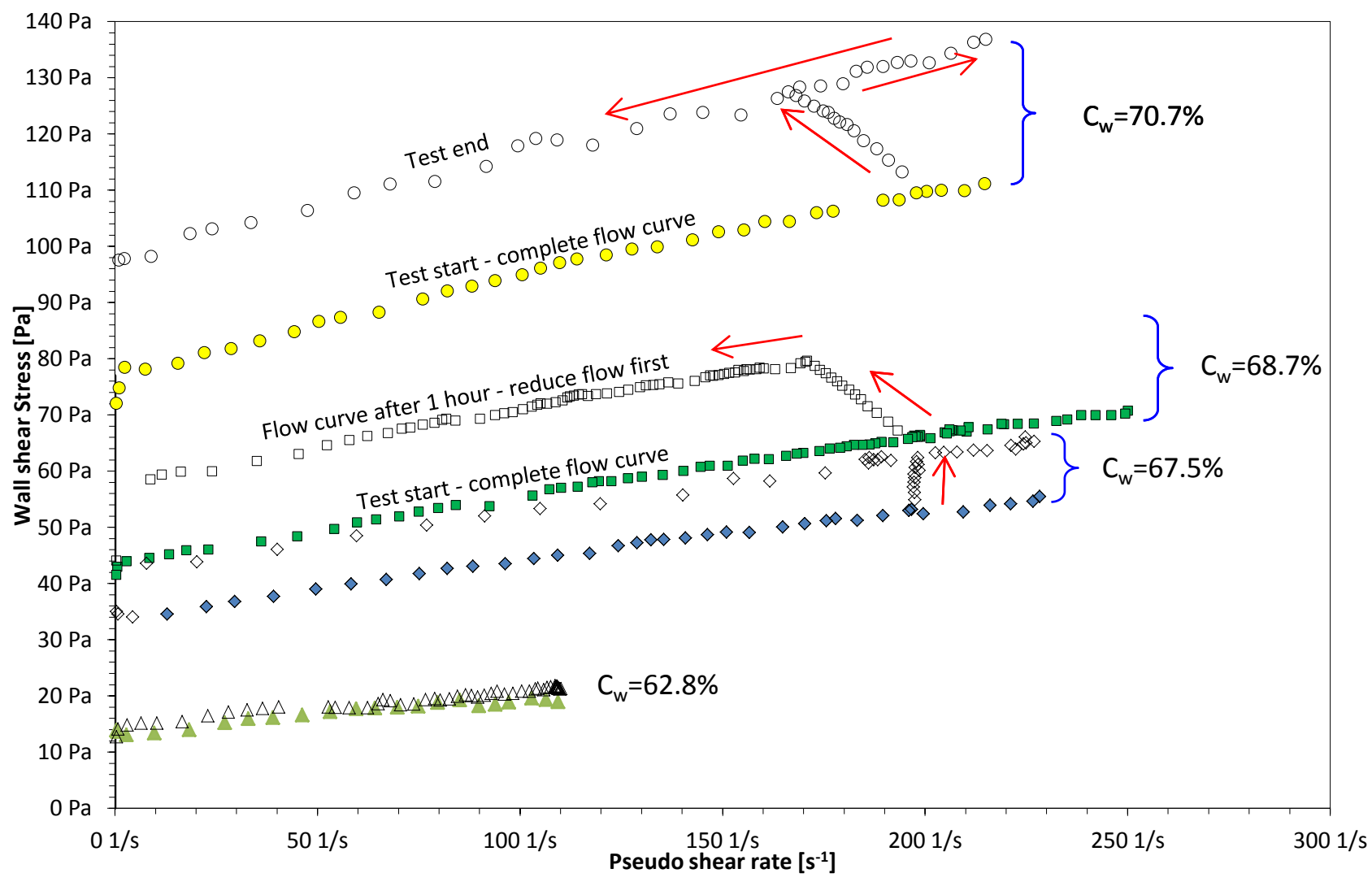

Figure 11 Laminar segregation - pseudo shear diagram for $100 \mathrm{~mm}$ pipe loop tests

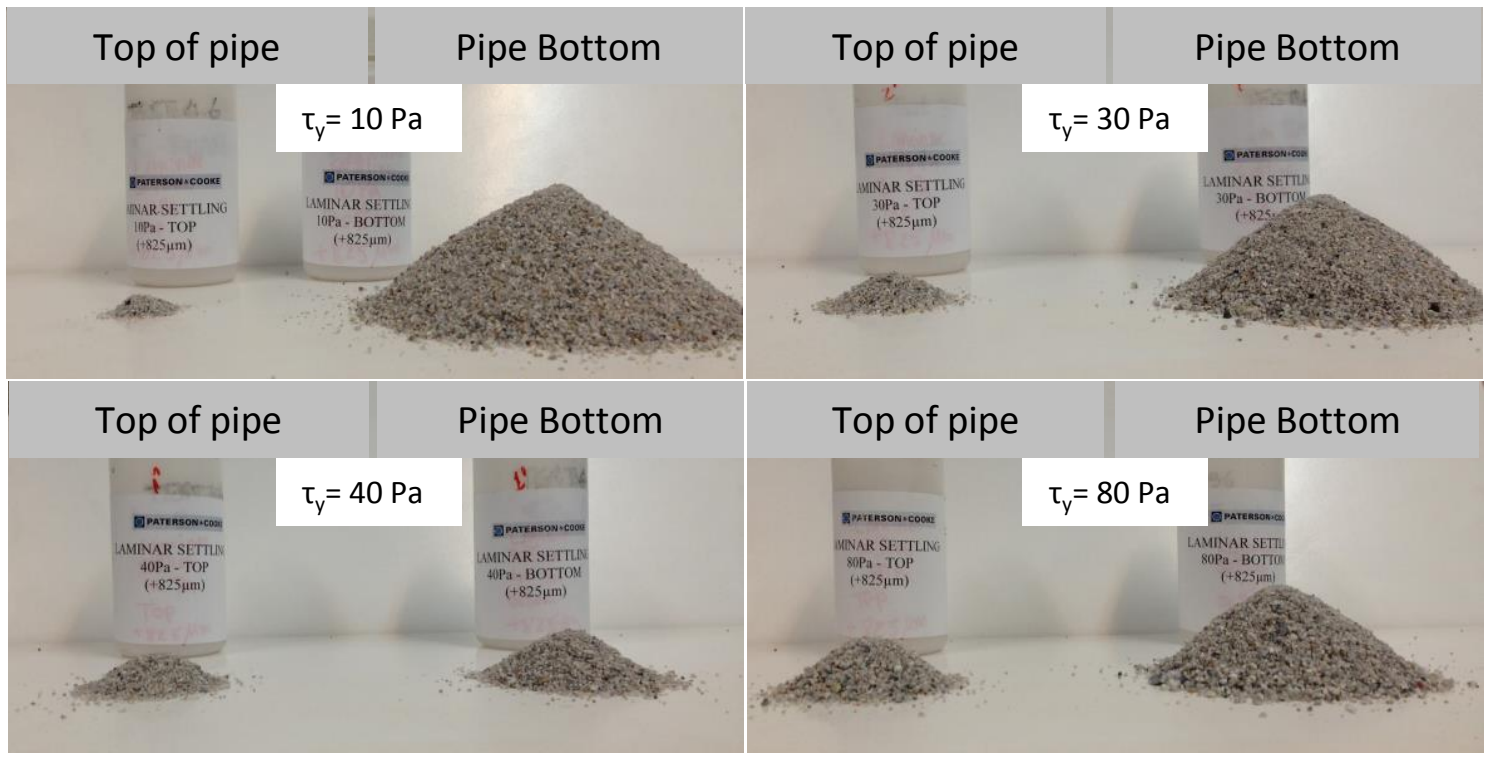

Figure 12 Laminar segregation test (samples taken from top and bottom of the pipe - sieved +825 $\mu \mathrm{m}$ ) 


\section{$5 \quad$ Conclusions}

As described in this paper, the pilot test work at Codelco's pipe loop was successful in completing the test plan, collecting good quality data and analysing the data to define the design basis for the transportation system. The pipe loop tests proved their usefulness in every aspect where the intention was to get information and key parameters for the industrial design.

In relation with the flow behaviour tests, it confirmed that caution must be taken if laminar flow operation is decided for the industrial transport pipelines. The re-start test showed that the pipelines must be flushed prior to a shut-down, alternatively the pump station must be capable of re-starting the pipeline considering that the pressure gradient requirement will be higher than normal operation.

In terms of lessons learned, the pilot pipe loop tests brought a lot of experience to the team and it confirmed the importance of doing pilot work for this type of project.

\section{Acknowledgements}

The authors thank Fritz van Sittert for his comments and contributions to this paper, as well as the personnel who assisted in completing the test work. The authors also thank Codelco for the permission to publish the information regarding the pilot plant tests at the Codelco Norte operation.

\section{References}

Brown, N.P. and Heywood, N.I. (eds) (1991) Slurry handling: Design of solid-liquid systems, in Elsevier Handling and Processing of Solids Series, London, $680 \mathrm{p}$.

Cooke, R. (2002) Laminar flow settling: The potential for unexpected problems, in Proceedings 15th International Conference on Hydrotransport, 3-5 June 2002, Banff, Canada, pp. 121-133.

Thomas, A.D. and Wilson, K.C. (2007) Rough-wall and turbulent transition analyses for Bingham plastics, in Proceedings 17th International Conference on Hydraulic Transport of Solids, 7-11 May 2011, The Southern African Institute of Mining and Metallurgy and the BHR Group, Cape Town, South Africa, pp. 77-86.

Walker, C.I. and Goulas, A. (1984) Performance characteristics of centrifugal pumps when handling non-Newtonian homogenous slurries, in Proceedings Institution of Mechanical Engineers, Vol. 198 A, pp. 41-49. 